\title{
The use of Interspinous Process Spacers in elderly people: preliminary experience
}

\author{
Nikolaos Syrmos,, Charalampos Iliadis, Vasilios Valadakis, Konstantinos Grigoriou, Dimitrios Arvanitakis \\ From $1^{\text {st }}$ International Congress on Neurobiology and Clinical Psychopharmacology and European \\ Psychiatric Association Conference on Treatment Guidance \\ Thessaloniki, Greece. 19-22 November 2009
}

\section{Background}

The spinous processes are located in the very back of the spinal column near the skin surface. In fact, by passing the hand down the center of the low back one is usually able to feel several small prominences. These are the spinous processes. The near proximity of the spinous processes to the skin allows for the implantation of interspinous process spacers with minimal operative intervention and spinal morbidity. The interspinous process devices are designed to distract (open) the foramen, where the nerve endings pass away from the center of the spinal region and into the legs. It is thought that these devices may also unload the intervertebral disc. They may limit spinal extension (the position the spine takes on when bending backward). This backward bending position may be painful for patients with spinal stenosis because it reduces the space available for the nerve roots in the exiting foraminal openings.The interspinous devices may be implanted with the patient under a mild sedative and local anesthesia as a day surgery procedure (patient goes home the same day) or under light anesthesia. This may be particularly beneficial for elderly patients for whom more extensive open surgery may present too great of a surgical risk due to less favorable general health and fitness level.

\section{Aim}

Aim of our study was to investigate the clinical outcome of patients with symptomatic lumbar spinal stenosis before and at periodic intervals after interspinous process spacers implantation.

\section{Materials and methods}

33 consecutive patients over 65 years old, were enrolled and surgically treated with interspinous process spacers

$$
\text { Neurosurgical Department, Venizeleio General Hospital, Heraklion, Crete, }
$$$$
\text { Greece }
$$

implantation implantation. They were clinically evaluated at the preoperative 1 month, 3-month, 6-month, 9 month and 1-year stage with clinical questionnaires (VAS, Zurich Claudication Questionnaire, Oswestry Disability Index, SF-36, JOA, AO SPINE ).

\section{Results}

13 patients failed to complete all the questionnaires at all time intervals and hence were excluded, leaving 20 patients who had completed all questionnaire at all time interval. By 12 months, $80 \%$ of these 20 patients -16 reported clinically significant improvement in their symptoms, 2 reported clinically significant improvement in physical function, and 2 expressed no satisfaction with the procedure.

\section{Conclusions}

The advantages of the interspinous process spacers are:

- Low Risk Operation

- Shorter Surgical Time

- Minimally Invasive Surgery

- Preserve Flexibility and Mobility

- Faster Rehabilitation

Published: 22 April 2010

\section{References}

1. Miller JD, Nader R: Treatment of combined osteoporotic compression fractures and spinal stenosis: use of vertebral augumentation and interspinous process spacer. Spine 2008, 33(19):E717-20.

2. Bono CM, Vaccaro AR: Interspinous process devices in the lumbar spine. $J$ Spinal Disord Tech 2007, 20(3):255-61.

3. Kim DH, Albert TJ: Interspinous process spacers. J Am Acad Orthop Surg 2007, 15(4):200-7.

doi:10.1186/1744-859X-9-S1-S86

Cite this article as: Syrmos et al:: The use of Interspinous Process

Spacers in elderly people: preliminary experience. Annals of General Psychiatry 2010 9(Suppl 1):S86. 